\title{
Simulation Modeling and Analysis of a Door Industry
}

Konstantinos Chronis, Department of Production and Management Engineering, Democritus University of Thrace, Greece Alexandros Xanthopoulos, Department of Production and Management Engineering, Democritus University of Thrace, Greece

(iD) https://orcid.org/0000-0002-7763-9860

Dimitrios E. Koulouriotis, Department of Production and Management Engineering, Democritus University of Thrace, Greece

\begin{abstract}
In this paper, the authors study the production line of a door industry. The first stage of this research consists of the detailed documentation with flow charts and systematization of all production processes, all product types, as well as all stages of production and equipment. The standard production times were calculated for each workstation, together with the relevant workforce requirements. In the second stage of this research, a discrete event simulation model of the factory was developed to assist in the production planning decision-making. The simulation model was verified using actual production data relating to 19 customer orders for a total of 1,281 doors. Four simulation experiments were executed, where the effect of alternative shifts on the manufacturing line's efficiency was investigated. The performance metrics of total production, mean daily production, and mean labor cost per product were considered. This experimental trial resulted in the identification of the shift configuration that achieves increased productivity while maintaining relatively low labor costs.
\end{abstract}

\section{KEYWORDS}

Discrete Event Simulation, Door Industry, Experimental Study, Process Modeling, Production Planning, Simulation Modeling, System Analysis

\section{INTRODUCTION}

This is an application-based research article focused on production planning with the aid of simulation. As such, it contributes in bridging the gap between theory and practice of production planning. Theoretical planning problems are largely stylized with many unrealistic and/or "convenient" assumptions from the perspective of the system modeler/analyst. An important motivation for this paper is to provide an inside view of a real-world manufacturer and to showcase the particularities and increased complexity of realistic production environments. Another important aim for this paper is to present the application of powerful computational techniques, in this case stochastic simulation, 
to model and solve production planning problems using a scientific approach rather than intuition and empirical knowledge

In this paper we examine a door manufacturer which is located in northern Greece. The company follows a "hybrid" make-to-stock/make-to-order production model which complicates significantly the production process/planning and it is distinctly differentiated from stylized, theoretical models that can be found in the relevant scientific literature. The make-to-order model generally applies to clients that are large hotel firms who require highly customized products. The make-to-stock model generally applies to individual clients or architectural firms that carry out some construction project (especially a small one) and typically select doors from a range of standardized, product types that are readily available from the door manufacturer

It is of paramount importance for the company to meet the customer due dates, i.e. deliver the ordered products at the promised dates. Furthermore, it is also very important to maintain high productivity levels, i.e. make use of the available resources as efficiently as possible. These goals call for effective production planning and control of production operations. There are several unique features of this door manufacturer that cause production planning to be a daunting task and are not normally found in synthetic/artificial problems that can be found in the relevant literature.

First of all, there is a very strong seasonality component in the demand for finished goods. This is due to the fact that the majority of orders stems from hotel firms and the high season for hotels in Greece is normally between April and September. This means that the bulk of related orders is normally placed in the period October - May causing a notable peak in the workload imposed on the plant at that time. Secondly, the plant constructs a large number of customized doors which in turn means that a significant fraction of its products has never been built before. This makes it very hard for the production planner to forecast actual machining times, personnel requirements etc. and it also entails the related learning curves in respect to the workers who will be engaged in production. Finally, there are significant limitations regarding the available space in the plant, both in terms of storage space as well as available workstations etc. These constraints further complicate the task of production planning, since blocking of some production stages may occur especially in periods when there is a demand surge.

Motivated by the aforementioned problems, this research article makes the following contributions:

- A systematic documentation and standardization of all production operations is carried out

- A realistic simulation model of the plant is developed and verified using real-life data

- A series of simulation experiments is conducted in order to study the effect of varying several production planning parameters on the production system's performance

- The goal of the authors is to aid the production planning function of the plant, which is largely empirical now, using state-of-the-art, computational methods.

The remainder of this article is structured as follows. In the "Background" section we cite a number of scholarly publications that are relevant to this research and compare them with this contribution. The next section ("Description of door manufacturer plant") offers a detailed description of the production operations that take place within the plant of the door manufacturer, including the various stages of the production line, the routing and processing times of alternative door types in the job-shop etc. The next section ("Simulation modelling of door manufacturer plant") describes the development/verification of the simulation model together with the parameters and results of the simulation experiments. The paper is concluded with the "Conclusion" section where directions for future research as well as limitations of this research are discussed. 


\section{BACKGROUND}

In this section, the authors provide a brief literature review of relevant works in order to position this article in relation to published literature. As mentioned in the introduction section, the examined production system has a number of singularities that differentiate it from idealized/theoretical models, nonetheless there are some distinguishing features that can facilitate its categorization into generic paradigms.

The interior and exterior doors produced in the plant are largely manufactured in batches and thus, the underlying production system can be categorized as a batch manufacturing plant. Problems pertaining to batch manufacturing are studied in Hong and Prabhu (2004) and Jurczyk-Bunkowska (2020), among others.

The examined door manufacturer follows a "hybrid" production model that lies somewhere between the intersection of the make-to-stock (MTS) and the make-to-order (MTO) paradigm. In a purely make-to-order system (Arredondo and Martinez, 2010), no stock of finished goods is kept and all production operations to manufacture some product are initiated after an actual customer order has been accepted. In a purely make-to-stock system the "opposite" situation holds. There exist some scholarly publications that treat hybrid MTS-MTO systems. The majority of these papers are theoretical contributions contrary to this research which is largely application-based. Several relevant works are cited hereafter. Beemsterboer et al. (2016) develop a Markov decision process (MDP) model of a two-product hybrid MTS-MTO system to decide when to switch from producing MTS parts to MTO parts. A similar approach (MDP) is also taken in the work of Wilson (2018). A radically different point of view can be found in Jia et al. (2017) who examine the simulation model of a (theoretical) flexible flowshop where the upstream stages (in relation to a "decoupling point") are MTS whereas the downstream stages follow the MTO paradigm. Romsdal et al. (2013) offer a theoretical discussion of tactical and operational implications of hybrid MTO-MTS production in the food industry. Another largely theoretical take on the subject is offered by Nagib et al. (2016) who review a large number of academic publications that examine hybrid MTS-MTO models in contrast to pure and MTS and MTO approaches.

As mentioned in the introduction, there is a very strong seasonality component in the demand for finished goods. The challenges that arise in a manufacturing environment in the presence of seasonal demand is examined, among others, in the works of Bhat and Krishnamurthy (2016), Mattsson (2010), Chang \& Chu (2013) and Ehrenthal et al. (2014).

Since the plant needs to be able to handle orders for highly customized doors, the production equipment needs to be general-purpose and the production operations in general need to be characterized by a significant level of flexibility. This is typical to job-shops, i.e. production systems with relatively low degree of automation that are suitable for rather low volume but flexible production. Production planning and scheduling problems pertaining to job shops are studied in Vinod and Sridharan (2011), Adibi et al. (2010) and Xanthopoulos et al. (2013), among others.

In this research, we utilize the Anylogic discrete event simulation software (Ivanov, 2017) to simulate the examined door manufacturing plant. Stochastic simulation is powerful tool with widespread application to production management problems. The reader is referred indicatively to the works of Katsios et al. (2017), Amaran et al. (2014) and Gocken et al. (2017).

\section{MAIN FOCUS OF THE ARTICLE}

\section{Description of Door Manufacturer Plant}

The case study in question pertains to a door manufacturer which is located in northern Greece and it has been active since the year 2000. The philosophy and corporate identity of this manufacturer revolves around three pillars a) excellent production quality and technical specifications, b) innovative culture and c) flexibility in order to adapt to changing customer needs. The manufacturer has developed 
aluminum casings that can fit to a range of wall widths which are particularly suitable for the Greek construction sector that has no standardized norms and door dimensions. It produces an extensive range of exterior doors with very high resistance to rain, sunlight and sea moisture. It can also deliver fireproof doors that can withstand up to 120 minutes of exposure to fire and sound insulated doors in the range of 28-38 db. It is the only company in Europe that holds a fireproofing certificate of 45 minutes for aluminum door casings and door wings. Its innovative designs and patents are registered with the Hellenic Industrial Property Organisation (OBI) and the company holds several fire resistant certifications from the international third party provider IFC Certification Ltd. Its clientele falls within three major categories: a) corporate clients, i.e. large hotel firms, b) architectural firms responsible for carrying out small or large construction projects and c) retail sales. The clientele mix of the company is roughly $85 \%, 10 \%$ and $5 \%$, meaning that the bulk of its production is targeted towards large, corporate clients. In the present time, the company has worked with over 200 hotel firms.

In this section, the authors offer a detailed description of the production operations that take place within the plant of the door manufacturer. More specifically, the authors state the firm's product portfolio, the various stages of the production line, the routing and processing times of alternative door types in the job-shop etc.

\section{Product Types}

All doors that are built by the firm can be customized to a large extent (e.g. in respect to dimensions, materials used, colors, fire resistance etc.). Nevertheless, with the exception of some highly-customized designs elaborated below, the door manufacturer's products can be classified to the following, broad, categories:

- Interior doors

- Aluminum casing and

- Wooden door wing

- Glass door wing

- Wooden casing and door wing

- Exterior doors

- Steel casing and door wing (armored doors)

- Aluminum casing and

- Aluminum door wing

- Wooden door wing

- Wooden casing and door wing

Interior doors with glass door wings are typically ordered by hotel firms to be used as shower doors. All-wooden interior doors are usually ordered in complex, non-standard colorings in response to the need to attain the desired stylistic effect by the customer. Exterior doors are usually requested by individual customers for their private real estates. Note that all-aluminum exterior doors are tailored to withstand extreme weather conditions including, intense sunlight, rain, sea breeze etc. The firm also has a substantial number of orders for highly customized doors e.g. for very particular openings etc. Figure 1 shows some examples of the door manufacturer's products.

\section{Description of Production Workflow}

In this section, the authors present the detailed workflow for building a finished product in the investigated door manufacturer. There are a few exceptions to the production process presented below which are cited hereafter. First, a substantial portion of the production for an armored door is outsourced; the door manufacturer only builds some wooden components of the door and offers the 
Figure 1. Examples of exterior doors with aluminum casings and door wings (on the left) and interior doors with wooden casings and door wings (on the right)
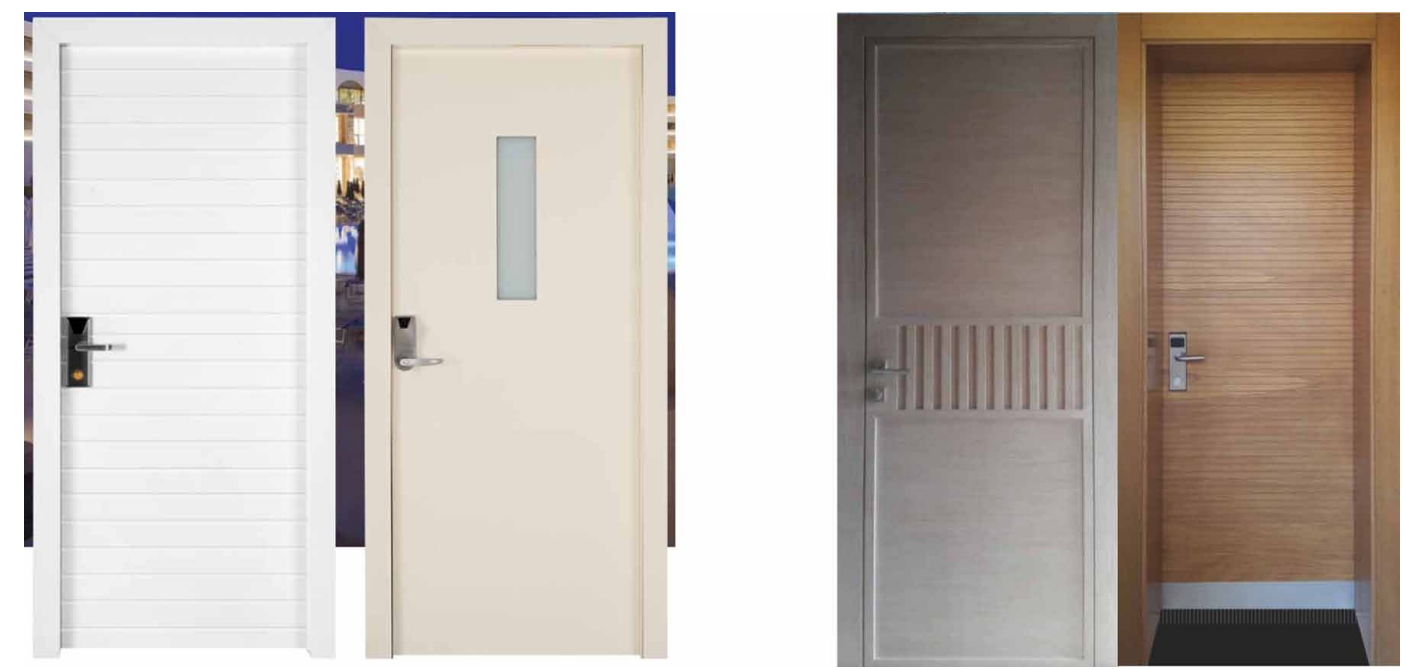

final assembly/packaging. Secondly, some highly customized designs follow an entirely different workflow that it is dictated by the specific needs of each customer.

In the remainder of this section we will focus on the primary production stages for manufacturing a "generic" door. Note that each product type has its unique routing in the shop floor and that aluminum doors have several distinctive differences in production compared to wooden doors. Nonetheless, in order to provide the general idea of the production workflow and save space, we will outline the manufacturing process of wooden doors with wooden casings in particular. In its entirety, the production workflow of the door manufacturer is depicted in Figure 2.

The whole procedure is initiated by drafting a written quotation for some customer. Once the two parties agree upon all details of the order, then the quotation is transformed into a contract that it is signed by both the customer and the door firm. The contract is a written statement of e.g. the product types and quantities ordered, the price for the goods that has been agreed, additional services provided by the door manufacturer etc. The contract is then forwarded to the production analysis/ planning department of the firm that generates the related order sheet. The order sheet contains technical information for the various production stages of the plant including dimensions and other manufacturing specifications, coloring instructions, information regarding positioning of locks and other attachments on the doors, fireproof specifications etc. The order sheet is drafted into three copies and each copy is sent to the three main production stages that the plant is comprised of. At the same time, relevant information is sent to the procurement department so as to ensure that all necessary raw materials are available on time. Note that the door manufacturer operates in a somewhat just-in-time mode regarding this aspect and maintains a rather negligible stock of raw materials.

Once the preparatory, yet very important previous steps have been completed, the actual production of the required end-items commences. Production is comprised of the following, serial, stages:

1. Carpenter shop

2. Sanding \& Dyeing

3. Assembly \& Packaging

The construction of a door starts at the carpenter shop with the production of the door wing frame. The frame is then filled with e.g. chipboard or fire resistant board. Aluminum or wooden 
Figure 2. The complete production workflow of the door manufacturer under study

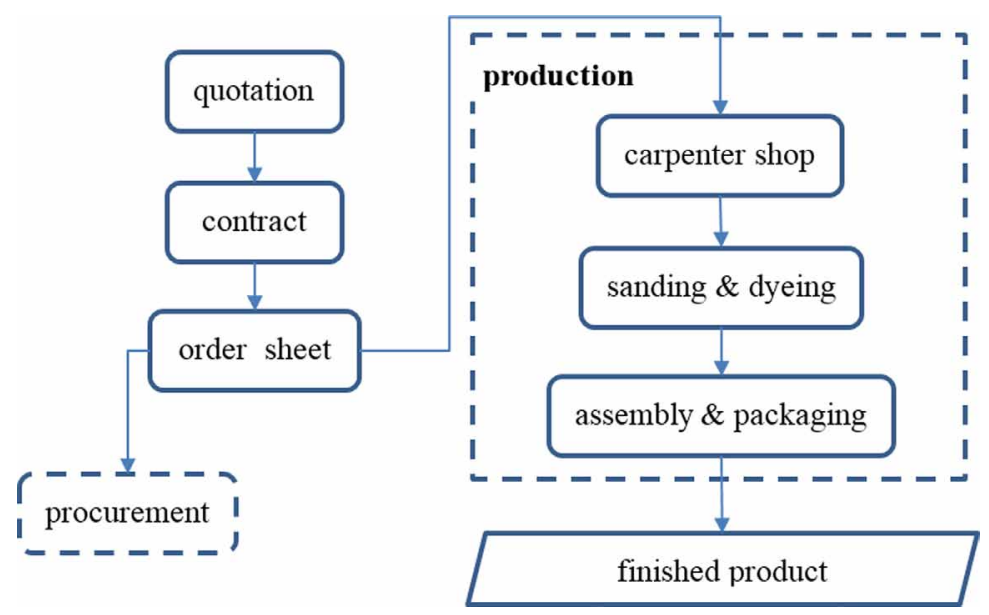

coatings are then applied on the door wing and the latter is forwarded to the press machine were it is subjected to $110 \mathrm{Bar} / \mathrm{cm}^{2}$ at $65-80$ degrees Celsius in order to bond. The door wing is allowed some time to cool and then it moves to the CNC machine were holes for locks etc. are drilled and to other workbenches for additional machining/finishing.

The next production stage is the sanding $\&$ dyeing shop. At this point, the door wing that was outputted by the carpenter shop is subjected to a series of sanding and dyeing operations which vary from one product type to another at a significant level. Dyed door wings need to spend a substantial amount of time in the furnace in order for the dyes to dry out.

The production of a door is completed in the assembly and packaging stage. First, the door casings are cut, assembled, dyed and processed in the CNC machines (note that aluminum door casings do not require dyeing). At the same time, locks and other metal fixtures are adjusted on the semi-finished door wings. Finally, the door wings and the related casings are assembled and sent to the packaging machine so as to become ready for dispatching.

The bottlenecks of the door manufacturing line are located in the $\mathrm{CNC}$ machine and mostly in the dyeing workstation. In the next section, the authors elaborate on these issues as well as on additional details of the production process.

\section{Description of Production Resources and Operations}

The chief production resources of the door manufacturer plant, categorized on the basis of the relevant production stage, are summarized in Table 1.

Figures 3-5 depict some indicative production equipment that is in the carpentry, sanding \& dyeing, assembly \& packaging stages of the door manufacturing line, respectively.

Table 1. Production resources of door manufacturing line

\begin{tabular}{|l|l|l|}
\hline Carpenter shop & Sanding \& Dyeing & Assembly \& Packaging \\
\hline CNC machine & 2 industrial furnaces & Automated packaging machine \\
Press machine & Sanding machine & Workbenches \\
Saw machine & Spray guns & Powertools \\
Workbenches & Workbenches & \\
Various powertools & Powertools & \\
\hline
\end{tabular}


Figure 3. Examples of production resources found in the carpenter shop. Press machine and workbenches (on the left) and CNC machine (on the right).
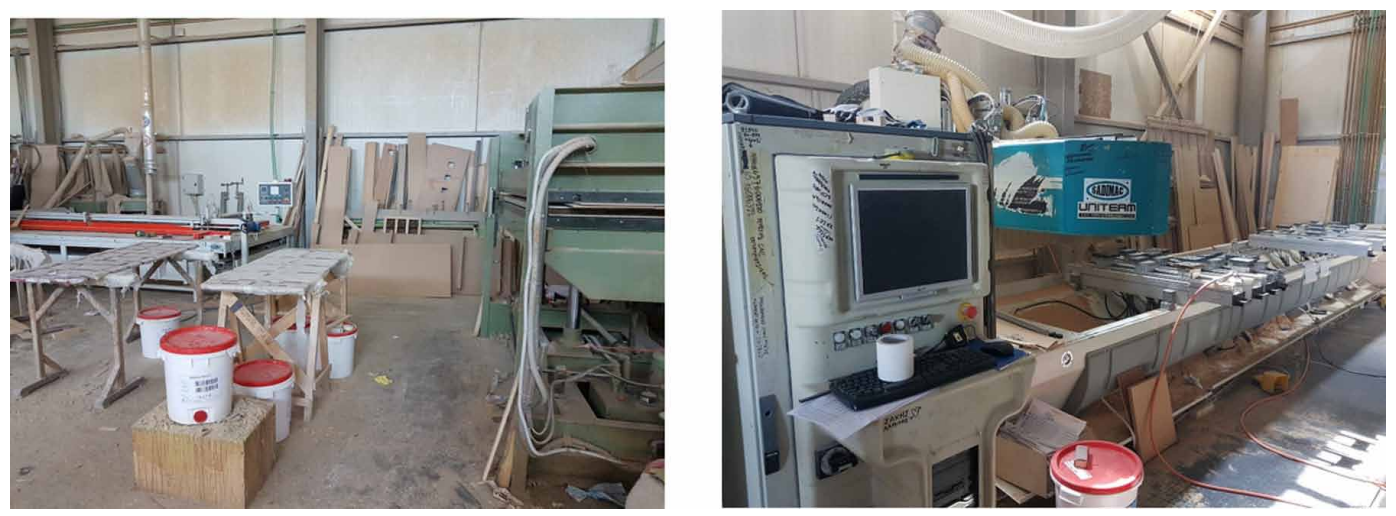

Figure 4. Examples of production resources found in sanding \& dyeing stage of the door production line. Sanding machine (on the left) and furnace (on the right).
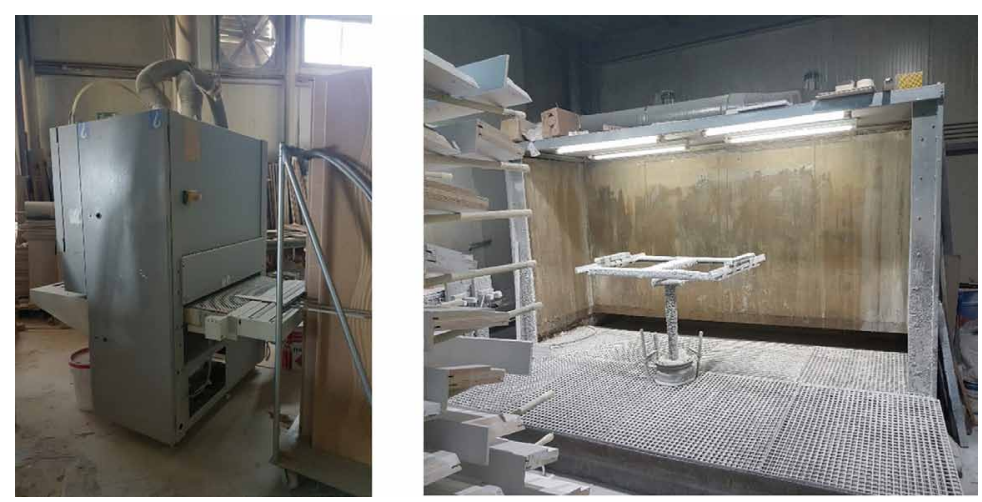

Figure 5. Examples of production resources found in assembly \& packaging stage of the door production line. Assembly workbenches (on the left) and packaging machine (on the right).
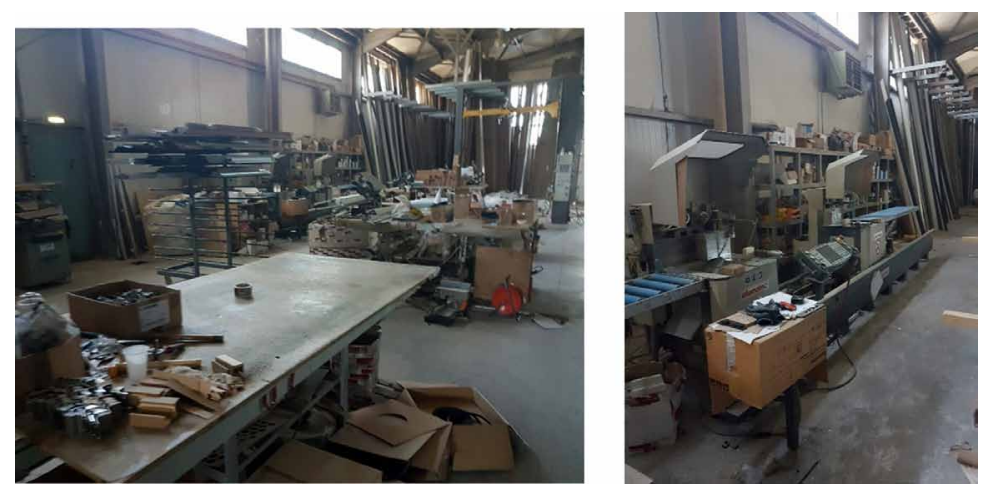
For the purposes of this research, the authors carried out a detailed documentation of all production operations. More specifically, for each production stage, all operations were documented including the relevant requirements for raw materials, workforce allocation and production times. Note that, as in all real-world production systems, service times vary due to unforeseen disturbances in the manufacturing process and thus, the recorded production times are actually mean values or "standard" times.

The aforementioned information is presented compactly in Tables 2-4 that correspond to the carpenter shop, the sanding \& dyeing stage and the assembly \& packaging stage, respectively.

By inspecting Table 2, one can observe the significant amount of time needed (14 h) for cooling/ drying after the door wings have been pressed. At that point, the pressed door wings exit the pressing machine with a temperature of roughly 50 degrees Celsius and are stacked horizontally, so that they are allowed to dry uniformly (from both sides). Finally, note the significant processing times in the $\mathrm{CNC}$ workstations which is one of the bottlenecks of the whole manufacturing line.

In Table 3, it is seen that the sanding/dyeing is the most time consuming process of the manufacturing line and the main bottleneck of the system.

In the assembly \& packaging stage, there are 2-9 workers, depending on the current workload of the plant. During the pre-processing of the door wings, locks, door hinges and other fixtures are attached on the door wing. A door casing is manufactured from a solid piece of aluminum or wood which is cut in three parts; these parts are machined so as to be ready to assemble with the door wing; finally, the parts are joined to form the door casing.

\section{SIMULATION MODELING OF DOOR MANUFACTURER PLANT}

As stated in the Introduction section, in order for the door manufacturer to be competitive, it must be able to deliver the ordered products on the promised due dates while maintaining the production process as efficient as possible and minimizing production costs. Effective production planning and control is needed in order to attain these goals. However, production planning and control is especially difficult for this plant because of the complexity of the manufacturing operations that were outlined in the previous section.

Table 2. Production operations and associated raw materials, required personnel and processing times for the carpentry stage ("capacity of pressing machine is 2 door wings)

\begin{tabular}{|c|c|c|c|}
\hline \multicolumn{4}{|c|}{ Carpenter shop } \\
\hline Production operation & Required materials & Required workers & Processing times \\
\hline $\begin{array}{l}\text { Door wing frame } \\
\text { construction }\end{array}$ & $\begin{array}{l}\text { Solid wood, chipboard, } \\
\text { fireproof board etc. }\end{array}$ & 1 & $5 \mathrm{~min}$ \\
\hline Pressing of door wings* & $\begin{array}{l}\text { D3 or D4 glue, coating } \\
\text { sheets, door wing frame }\end{array}$ & 2 & $\begin{array}{l}9 \mathrm{~min} \text { (4 mm pressing) or } \\
12 \mathrm{~min}(6 \mathrm{~mm} \text { pressing })+ \\
14 \mathrm{~h} \text { (cooling/drying time) }\end{array}$ \\
\hline $\begin{array}{l}\text { Machining/finishing of } \\
\text { door wings }\end{array}$ & Door wing & 2 & $5 \mathrm{~min}$ \\
\hline CNC machining & Door wing & 1 (+1 for loading) & $\begin{array}{c}3 \text { min (simple lock) or } 7 \\
\text { min (hotel lock) }+4 \text { min } \\
\text { (door hinge machining) }+ \\
2-20 \text { min (for pantographic } \\
\text { designs, if any) }+3 \text { min } \\
\text { (loading) }\end{array}$ \\
\hline $\begin{array}{l}\text { Final machining/finishing } \\
\text { or welding }\end{array}$ & Door wing & $\begin{array}{c}\text { (+1 for loading, if } \\
\text { necessary) }\end{array}$ & $5 \min$ \\
\hline
\end{tabular}


Table 3. Production operations and associated raw materials, required personnel and processing times for the sanding and dyeing stage

\begin{tabular}{|c|c|c|c|}
\hline \multicolumn{2}{|c|}{ Sanding \& Dyeing } \\
\hline Production operation & Required materials & Required workers & Processing times \\
\hline sanding & Putty, sealer, surfacer & $1-5$ & $\begin{array}{c}7-25 \text { min (depending on } \\
\text { product type) }\end{array}$ \\
\hline dyeing & Various dyes & 4 (2 workers/furnace) & $\begin{array}{c}10 \text { min (for dyeing each } \\
\text { door wing side) }\end{array}$ \\
\hline Furnace processing & Door wing & 4 (2 workers/furnace) & $\begin{array}{c}4-6 \mathrm{~h} \text { (for the surfacer to } \\
\text { dry), } 40 \text { min-1.5 } \mathrm{h} \text { (for } \\
\text { water dyes to dry), 3-5 } \mathrm{h} \\
\text { (for sealer to dry), 3-5 (for } \\
\text { final dye to dry) }\end{array}$ \\
\hline
\end{tabular}

Table 4. Production operations and associated raw materials, required personnel and processing times for the assembly and packaging stage

\begin{tabular}{|c|c|c|c|}
\hline \multicolumn{4}{|c|}{ Assembly \& Packaging } \\
\hline Production operation & Required materials & Required workers & Processing times \\
\hline $\begin{array}{l}\text { Pre-processing of door } \\
\text { wing for assembly }\end{array}$ & $\begin{array}{c}\text { Door wing, locks, door } \\
\text { hinges, additional fixtures } \\
\text { and ornaments (if any), } \\
\text { glue }\end{array}$ & $1-2$ & $5-15 \mathrm{~min}$ \\
\hline $\begin{array}{l}\text { Production of aluminum } \\
\text { door casing }\end{array}$ & Aluminum, bolts etc. & $1-2$ & $13 \mathrm{~min}$ \\
\hline $\begin{array}{c}\text { Production of wooden door } \\
\text { casing }\end{array}$ & Solid wood, bolts etc. & $1-2$ & $16 \mathrm{~min}$ \\
\hline Final assembly & Door wing and door casing & 2 & $5 \mathrm{~min}$ \\
\hline Packaging & Finished door & 1 & $2.5 \mathrm{~min}$ \\
\hline
\end{tabular}

In order to aid this function, the authors developed a simulation model of the door manufacturing line that can mimic the operation of the actual system in detail. Using simulation, one can experiment with alternative control parameters and observe the performance of the system without taking any risks (as it would be the case if one experimented with the actual system). This way, alternative scenarios can be examined and the optimal production planning decisions can be identified. These decisions can then be used to guide decision-making in the real-world system in order improve its performance.

\section{Development of Simulation Model}

The door manufacturing plant belongs to the class of discrete event systems. A discrete event system is a dynamic and stochastic system with discrete state space. The state of such a system changes only at the occurrence of specific events. The examined system is a continuous time system i.e. the system state remains unchanged at any time point and "jumps" instantaneously to a new state whenever an admissible event occurs.

In order to model a discrete event system, discrete event simulation can be used. A discrete event simulator essentially generates "sample paths" of the system's dynamic evolution, i.e. sequences of state transitions with the passage of time. For a stochastic system, multiple simulations are executed 
Table 5. Data table for the activities in the assembly phase (refer to Figure 6)

\begin{tabular}{|l|c|c|c|c|c|c|c|}
\hline & \multicolumn{2}{|c|}{$\begin{array}{c}\text { Time in min } \\
\text { (triangular } \\
\text { distribution) }\end{array}$} & Workers & Machines & Location & Capacity \\
\hline $\begin{array}{l}\text { proetoimasia_thyrofyllou } \\
\text { (doorleaf preparation) }\end{array}$ & 2 & 3 & 4 & 2 & - & proetoimasia_fyllou & 2 \\
\hline koph_faltswn (frame cutting) & 3 & 4 & 5 & 1 & $\begin{array}{c}\text { Aluminium } \\
\text { Cutter }\end{array}$ & $\begin{array}{c}\text { faltsopriono_kai_ } \\
\text { pagkos }\end{array}$ & 1 \\
\hline $\begin{array}{l}\text { anoigma_antikrismatos (lock } \\
\text { drilling) }\end{array}$ & 3 & 3.5 & 4 & 1 & - & antikrisma & 1 \\
\hline presaki (drilling for connectors) & 1.5 & 2 & 2.5 & 1 & - & presaki8 & 1 \\
\hline $\begin{array}{l}\text { montarisma_kasas (frame } \\
\text { assembly) }\end{array}$ & 3 & 4 & 5 & 1 & - & montarisma_kasas8 & 1 \\
\hline $\begin{array}{l}\text { combine1 (door leaf and frame } \\
\text { final assembly) }\end{array}$ & 3 & 4 & 5 & 2 & - & pagkoi_tel_mont & 2 \\
\hline
\end{tabular}

with the same parameters and the observed system performance is aggregated in order to acquire useful numerical results.

For the purposes of this research, the Anylogic simulation software was utilized in order to build the simulation model of the door manufacturing plant. Anylogic offers a GUI were simulation models can be built by a) inserting the appropriate simulation blocks in the model and b) setting the parameters of the simulation blocks to the suitable values so as to implement the required simulation logic. Anylogic also allows for the actual schematics of the simulated system to be embedded in the model as well as for basic animation functionalities, and this adds to achieving a more realistic simulation.

The Anylogic simulation model of the door manufacturing plant essentially comprises of three parts (Carpentry stage, sanding \& dyeing stage, assembly \& packaging stage) just like the actual system. In Figure 6 (left part) we see the part of the simulation model that implements the assembly stage and in the lower part of Figure 6 one can see the graphic, "front-end", representation of the model. Table 5 contains the parameters of the simulation blocks depicted on the left side of Figure 6 (note that this is a stochastic simulation model and thus, processing times are random variables). The remaining production stages are implemented in a similar fashion and they are omitted in order to save space.

Figure 6. Implementation of the assembly stage of the manufacturing plant in Anylogic (left) and the graphical component of this implementation (right).

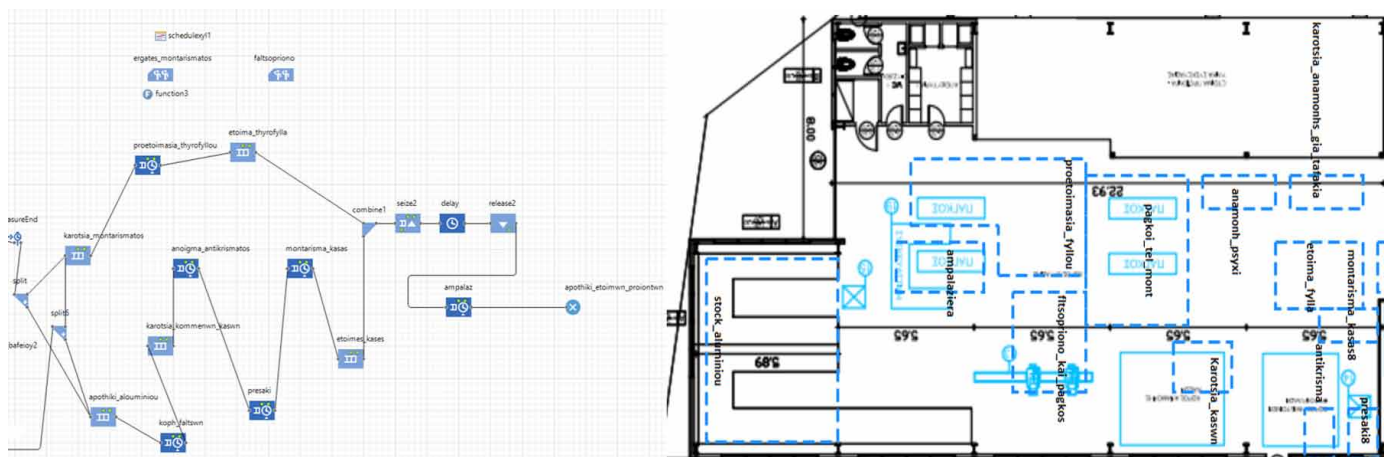




\section{Verification of Simulation Model}

In order for any simulation model to be useful in practice, it must be able to mimic reality accurately. To ascertain this, we compare the simulation model's output against actual production data of the plant; this task is commonly known as model verification.

We used production data for 1 month (roughly 30 working days) from the period 16/3/2018$23 / 3 / 2018$. This data pertained to orders from 19 customers for 4 door types where $33 \%$ of the total ordered products belongs to two major hotel firms. The total number of ordered products was 1281 doors where $34 \%$ of which was doors with wooden casings and door wings.

The simulation model was executed for a duration of 1 month, using triangular processing times with means from Tables 2-4 and one day shift (7:00-15:00) of 23 workers in total. The total throughput that was computed by the simulation model matched closely the actual production of the plant and this gave evidence that the dynamics of the manufacturing plant were accurately captured by the simulation model.

Figure 7 presents a snapshot of the simulation model at execution time. In Figure 7, grey and brown "boxes" represent work-in-progress, i.e. currently processed doors with aluminum and wooden door wings, respectively. Workstations that are subjected to heavy workload (e.g. CNC machine, Press Machine and sanding/dyeing stages) are highlighted as red. Finally, colored dots represent raw materials (e.g. raw wood, chipboards etc.) and workers.

\section{Simulation Experiments and Analysis}

Four simulation experiments were executed (refer to Table 6) where the effect of alternative shifts on the manufacturing lines efficiency was investigated. The duration of all simulation experiments was 31 days, the mean processing times that were calculated in section "Description of production resources and operations" were used as well as a worker wage equal to 45 euro/day.

Figure 7. View of the door manufacturing plant's simulation model at execution time

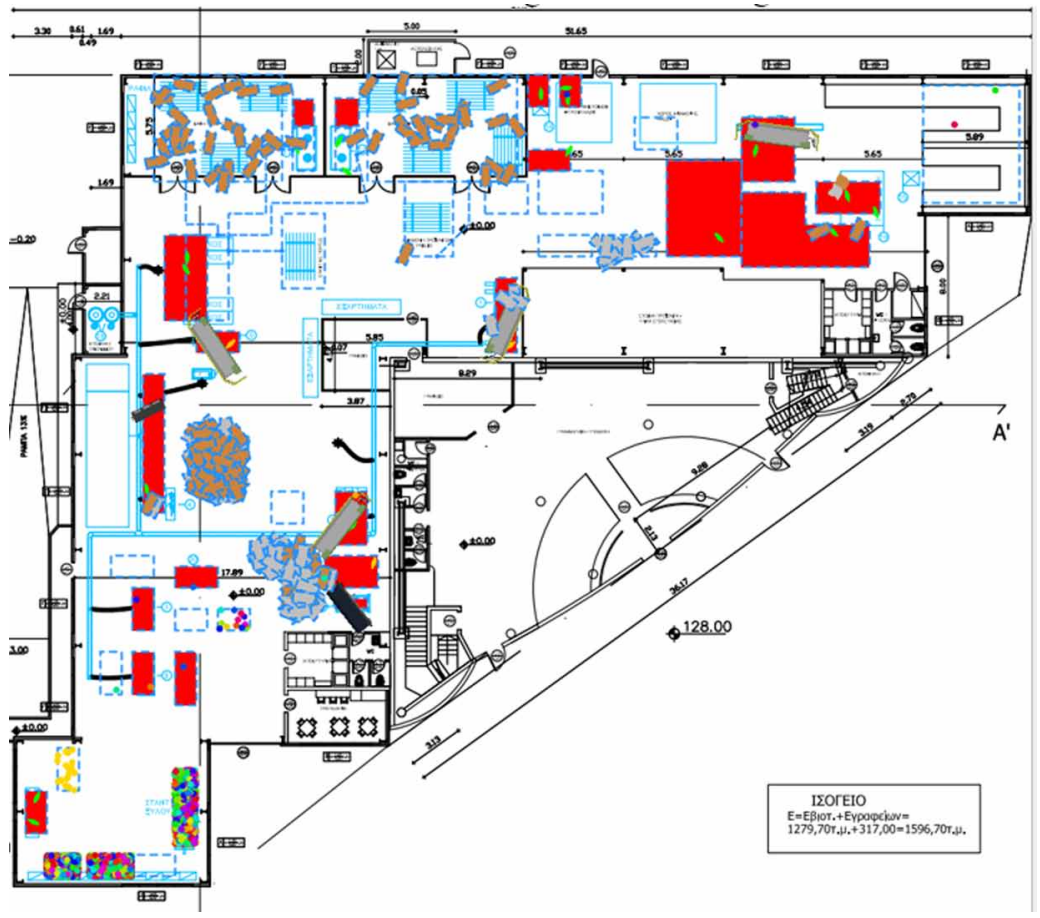


Table 6. Independent variables of the four simulation cases

\begin{tabular}{|c|c|c|c|c|c|c|c|}
\hline Case 1 & \multicolumn{2}{|c|}{ Case 2} & \multicolumn{3}{|c|}{ Case 3} & \multicolumn{2}{|c|}{ Case 4} \\
\hline $\begin{array}{c}\text { Shifts \& number of } \\
\text { workers }\end{array}$ & \multicolumn{2}{|c|}{$\begin{array}{c}\text { Shifts \& number of } \\
\text { workers }\end{array}$} & \multicolumn{3}{|c|}{ Shifts \& number of workers } & \multicolumn{2}{|c|}{$\begin{array}{c}\text { Shifts \& number of } \\
\text { workers }\end{array}$} \\
\hline 7:00-15:00 & $7: 00-15: 00$ & $\begin{array}{l}15: 00- \\
23: 00\end{array}$ & 7:00-15:00 & $\begin{array}{l}15: 00- \\
23: 00\end{array}$ & $\begin{array}{c}23: 00- \\
7: 00\end{array}$ & 7:00-15:00 & $19: 00-3: 00$ \\
\hline 23 & 23 & 23 & 23 & 23 & 23 & 23 & 23 \\
\hline
\end{tabular}

All simulation experiments pertained to saturated systems, i.e. systems were demand exceeds plant capacity, in order to estimate the maximum attainable throughput of the system. The performance metrics of a) total production (throughput), b) mean daily production and c) mean labor cost per product were considered (refer to Table 7).

The experimental results suggest that the best system configuration is that of case 4 since it achieves increased productivity compared to case 2 (which also has 2 shifts) but with labor costs that are directly comparable to case 1 (that has only one shift). The reason why case 4 is superior to other configurations can be sought in the fact that are 4 hours of idle in between the two shifts. In this 4-hour window, currently processed doors can be allowed to cool/dry. This way, the next shift can readily process them without any delays.

Present your perspective on the issues, controversies, problems, etc., as they relate to theme and arguments supporting your position. Compare and contrast with what has been, or is currently being done as it relates to the article's specific topic and the main theme of the journal.

\section{CONCLUSION}

In this research, the manufacturing line of a plant that builds interior and exterior doors was studied. Initially, all production stages were documented and the production process was analyzed in its entirety. At that phase of this research, standard processing times for each workstation as well as workforce and raw material requirements were computed.

Moving further, the simulation model of the plant was developed using the functionalities of the Anylogic discrete event software. The simulation model was verified using actual production data for orders of 19 customers, 4 door types and 1281 doors in total.

Four simulation experiments were conducted were we studied the effect of modifying the shifts on the efficiency of the production line. The numerical results suggested that the best solution is a scheme with 2 shifts per workday, were the second shifts starts 4 hours after the first shifts ends.

Table 7. Results of four simulation experiments

\begin{tabular}{|c|c|c|c|c|}
\hline & Case 1 & Case 2 & Case 3 & Case 4 \\
\hline $\begin{array}{c}\text { Total production } \\
\text { (wooden doors) }\end{array}$ & 779 & 1484 & 2145 & 1500 \\
\hline $\begin{array}{c}\text { Total production } \\
\text { (aluminum doors) }\end{array}$ & 815 & 1508 & 2183 & 101 \\
\hline $\begin{array}{c}\text { Mean daily } \\
\text { production }\end{array}$ & 51 & 97 & 140 & 20.6 \\
\hline Labor costs/product & 20.1 & 21.4 & 22.2 & 101 \\
\hline
\end{tabular}


This research can be extended in several ways. A straightforward direction is to conduct additional experimental trials and examine further input and output variables. For example, it would be interesting to examine several other performance metrics such as average work-in-process and finished goods inventories (so as to identify potential bottlenecks in the manufacturing process) as well as the utilization of production equipment and personnel. Metrics that are related to customer service would also be of interest, e.g. averge order lead time, average tardiness/lateness of orders etc. Additional what-if-scenarios that relate to, e.g. additional storage space, additional parallel workstations and/or machines could also be examined.

More elaborate extensions of this research could entail the following. The discrete-event simulation models of the plant could be augmented/interfaced with optimization algorithms to provide advanced production planning/scheduling functionalities. It would be also interesting to interface the plant simulation models with real-time condition monitoring systems in the shop floor so as to obtain a "digital twin" of the examined factory which could be utilized for real-time and decision-making, from a production planning perspective.

The major limitations of this research pertain to the "abstraction" of several features of the real-world system, i.e. the exclusion of some of its characteristics from the simulation model. More specifically, in this simulation study we do not examine i) the product range of the plant in its entirety (refer to section product types), ii) or highly customized door designs that require a unique workflow in the shop floor iii) or outsourcing considerations (e.g. the procurement of specific door components from external sources). These abstractions were deemed necessary so as to limit the complexity of the simulation model and render the interpretation of the experimental results manageable. 


\section{REFERENCES}

Adibi, M. A., Zandieh, M., \& Amiri, M. (2010). Multi-objective scheduling of dynamic job shop using variable neighborhood search. Expert Systems with Applications, 37(1), 282-287. doi:10.1016/j.eswa.2009.05.001

Amaran, S., Sahinidis, N.V., Sharda, B., \& Bury, S.J. (2014). Simulation optimization: a review of algorithms and applications. 4OR - A Quarterly Journal of Operations Research, 12(4), 301-333.

Arredondo, F., \& Martinez, E. (2010). Learning and adaptation of a policy for dynamic order acceptance in make-to-order manufacturing. Computers \& Industrial Engineering, 58(1), 70-83. doi:10.1016/j.cie.2009.08.005

Beemsterboer, B., Land, M., \& Teunter, R. (2016). Hybrid MTO-MTS production planning: An explorative study. European Journal of Operational Research, 248(2), 453-461. doi:10.1016/j.ejor.2015.07.037

Bhat, S., \& Krishnamurthy, A. (2016). Interactive effects of seasonal-demand characteristics on manufacturing systems. International Journal of Production Research, 54(10), 2951-2964. doi:10.1080/00207543.2016.1138150

Chang, C. T., \& Chou, H. C. (2013). A coordination system for seasonal demand problems in the supply chain. Applied Mathematical Modelling, 37(6), 3674-3686. doi:10.1016/j.apm.2012.07.061

Ehrenthal, J. C. F., Honhon, D., \& Woensel, T. V. (2014). Demand seasonality in retail inventory management. European Journal of Operational Research, 238(2), 527-539. doi:10.1016/j.ejor.2014.03.030

Gocken, M., Dosdogru, A., \& Boru, A. (2017). Optimization via simulation for inventory control policies and supplier selection. International Journal of Simulation Modelling, 16(2), 241-252. doi:10.2507/IJSIMM16(2)5.375

Hong, J., \& Prabhu, V. V. (2004). Distributed reinforcement learning control for batch sequencing and sizing in justin-time manufacturing systems. Applied Intelligence, 20(1), 71-87. doi:10.1023/B:APIN.0000011143.95085.74

Ivanov, D. (2017). Operations and supply chain simulation with Anylogic. Berlin School of Economics and Law.

Jia, Y., Weng, W., \& Fujimura, S. (2017). A hybrid MTS-MTO production model with a dynamic decoupling point for flexible flow shops. 2017 IEEE/ACIS $16^{\text {th }}$ International Conference on Computer and Information Science (ICIS), Wuhan, 2017, 803-807.

Jurczyk-Bunkowska, M. (2020). Using discrete event simulation for planning improvement in small batch size manufacturing system. In G. Krolczyk, M. Wzorek, A. Krol, O. Kochan, J. Su, \& J. Kacprzyk (Eds.), Sustainable Production: Novel trends in energy, environment and material systems. Studies in systems, decision and control (Vol. 198, pp. 19-43). Springer. doi:10.1007/978-3-030-11274-5_3

Katsios, D., Xanthopoulos, A. S., Koulouriotis, D. E., \& Kiatipis, A. (2018). A simulation optimization tool and its production/inventory control application. International Journal of Simulation Modelling, 17(2), 257-270. doi:10.2507/IJSIMM17(2)425

Mattsson, S. A. (2010). Inventory control in environments with seasonal demand. Operations Management Research, 3(3-4), 138-145. doi:10.1007/s12063-010-0035-1

Nagib, A. N. M., Adnan, A. N., Ismail, A., Halim, N. H. A., \& Khusaini, N. S. (2016). The role of hybrid make-to-stock (mts) - make-to-order (mto) and economic order quantity (eoq) inventory control models in food and beverage processing industry. IOP Conference Series. Materials Science and Engineering, 160, 012003. doi:10.1088/1757-899X/160/1/012003

Romsdal, A., Arica, E., Strandhagen, J. O., \& Dreyer, H. C. (2013). Tactical and operational issues in a hybrid mto-mts production environment: the case of food production. In C. Emmanouilidis, M. Taisch, \& D. Kiritsis (Eds.), APMS 2012, Part II, IFIP AICT 398 (pp. 614-621). Springer. doi:10.1007/978-3-642-40361-3_78

Vinod, V., \& Sridharan, R. (2011). Simulation modelling and analysis of due-date assignment methods and scheduling decision rules in a dynamic job shop production system. International Journal of Production Economics, 129(1), 127-146. doi:10.1016/j.ijpe.2010.08.017

Wilson, S. (2018). Mix flexibility optimization in hybrid make-to-stock/make-to-order environments in process industries. Cogent Engineering, 5(1), 1501866. doi:10.1080/23311916.2018.1501866

Xanthopoulos, A. S., Koulouriotis, D. E., Tourassis, V. D., \& Emiris, D. M. (2013). Intelligent controllers for bi-objective dynamic scheduling on a single machine with sequence-dependent setups. Applied Soft Computing, 13(12), 4704-4717. doi:10.1016/j.asoc.2013.07.015 
A. S. Xanthopoulos received the M.S. and Ph.D. degrees in production and management engineering from the Democritus University of Thrace, Xanthi, Greece in 2006 and 2010, respectively. Currently, he is Assistant Professor with the Department of Production and Management Engineering, Democritus University of Thrace, Xanthi, Greece. $\mathrm{He}$ is the author of one book, four book chapters and over ten articles. His research interests include stochastic manufacturing systems, production/inventory control, dynamic sequencing, maintenance scheduling, discrete-event simulation, Markov chains, evolutionary algorithms, and reinforcement learning.

Dimitrios E. Koulouriotis received his Ph.D. in Intelligent Systems from Department of Production and Management Engineering, Technical University of Crete, Greece, in 2001. He received the Diploma in Electrical and Computer Engineering at the Democritus University of Thrace and the M.S. in Electronic and Computer Engineering at the Technical University of Crete, in 1993 and 1996, respectively. He is currently in the Department of Production and Management Engineering, Democritus University of Thrace, as a Full Professor and Director of Industrial Production Laboratory and Logistics Laboratory. His research interests include computational intelligence, machine learning and pattern recognition and their applications in vision, image and signal processing, robotics, and industrial engineering. He has published over 150 research papers in these areas, and he served as a chair, board member and reviewer to several of scientific journals and conferences. 